\title{
Seroprevalence of chikungunya fever in a tertiary care hospital in North Karnataka
}

\author{
Mahesh Kumar S. ${ }^{1}$, Uma Chikkaraddi ${ }^{2, *}$, Smitha N. R. ${ }^{3}$, Divya A. ${ }^{4}$ \\ ${ }^{\mathbf{1}}$ Associate Professor, ${ }^{\mathbf{2}}$ Tutor, ${ }^{\mathbf{3}}$ Post graduate, ${ }^{\mathbf{4}}$ Junior Resident, Dept. of Microbiology, ${ }^{\mathbf{1}, \mathbf{3}}$ Karnataka Institute of Medical Sciences, \\ Hubballi, Karnataka, ${ }^{2}$ Belagavi Institute of Medical Sciences, Belgaum, Karnataka, ${ }^{4}$ National Institute of Mental Health and \\ Neurosciences, Bangalore, Karnataka, India
}

*Corresponding Author:

Email: ucumasiri@gmail.com

\begin{abstract}
Introduction: Chikungunya disease is caused by Chikungunya virus, an Alpha virus under the family Togaviridae, transmitted through the vector Aedes spp. mosquitoes. The sudden onset of very high fever along with rash and severe arthralgia are the main symptoms. It's a major public health problem similar to other arboviral diseases like Dengue and Japanese B encephalitis infections.

Materials and Methods: A cross sectional study was conducted at a tertiary care hospital in north Karnataka. Serum samples of 555 suspected cases of Chikungunya fever were tested for Chikungunya IgM antibodies by ELISA (from NIV, Pune) over a period of 4 years, from January 2013 to December 2016.

Results: Of the 555 serum samples tested, 128 (23.06\%) were positive for Chikungunya IgM antibodies. The most affected age group was 21 to 30 years $35(27.34 \%)$, followed by 31 to 40 years $26(20.31 \%)$. Male to female ratio was $1: 1.56$. Of the seropositive cases, all the cases presented with the history of fever and joint pain. The maximum number of cases were seen during the monsoon i.e. June 32 (25\%), followed by the post monsoon period September $26(20.31 \%)$.)

Conclusions: The seroprevelance of Chikungunya cases in the present study is $23.06 \%$ with high prevalence in the monsoon and post monsoon months affecting the productive age group of the population. This reiterates the fact that Chikungunya continues to be a major health concern in our setting and indicates the need for appropriate strategies to reduce the severity of disease.
\end{abstract}

Keywords: ELISA, Serology, Joint pain, Tagoviridae, IgM.

\section{Introduction}

Chikungunya disease is a vector born infection caused by Chikungunya virus a single-stranded RNA Alpha virus from the family Togaviridae, the vector being Aedes species mosquitoes. ${ }^{1}$ Chikungunya virus Isolated in humans and Aedes aegypti mosquitoes in Tanzania in $1952 .^{2}$ The name CHIK is derived from the Makonde word which means "that which bends up" describing the stooped posture due to arthritic feature of the disease. ${ }^{2}$ The present epidemic in India started during December 2005 and the country has so far experienced more than 11,00,000 Chikungunya cases from several Indian states including Andhra Pradesh, Maharashtra, Karnataka, Tamil Nadu and Madhya Pradesh. ${ }^{3,4}$ Resurgence of Chikungunya has been attributed to various factors including globalization, increase in the mosquito population, loss of herd immunity and the mutation $\mathrm{A} 226 \mathrm{~V}$ in the $\mathrm{E} 1$ gene causing a significant increase in Chikungunya viral infectivity for Aedes Albopictus. ${ }^{5}$ Chikungunya disease has no animal reservoirs. ${ }^{2}$ The Chikungunya fever presents with triad of symptoms fever, arthralgia and rashes. Diagnosis of Chikungunya fever is mainly based on the Clinical findings whereas the confirmation of the infection is done only by the laboratory investigations. Serodiagnosis is the most common approach for the diagnosis of the Chikungunya infection where the IgM antibodies against Chikungunya Virus are detected. Other reliable modes of laboratory diagnosis include the molecular methods like RT-PCR.
In the view of changing trends in the seroprevelance of Chikungunya disease with respect to the geographical area, successive years of the study period, seasonal variations, severity of the patients and need for hospitalization, this study has been under taken to know the seroprevelance of Chikungunya disease in the tertiary care centre of north Karnataka.

\section{Materials and Methods}

A cross sectional study conducted over a period of four years from January 2013 to December 2016 at a tertiary care centre in north Karnataka, Karnataka Institute of Medical Sciences Hubballi. Serum samples of patients clinically suspected to have Chikungunya infection were subjected to IgM Capture ELISA for the detection of IgM Anti - Chikungunya antibodies using IgM antibody capture ELISA kit produced by National Institute of Virology, Pune (Arbovirus Diagnostic NIV, Pune, India). The tests were carried out following the manufacturer instruction.

\section{Results}

A total of 555 serum samples were tested, of which $128(23.06 \%)$ of the samples were positive for Anti Chikungunya IgM antibodies. Highest occurrence of Chikungunya cases was seen in the year of 2013 (33.08\%), least being in $2016(08.57 \%)$ (Image I). All the age groups from 0-90 years were affected, of which the most affected age group was 21-30 years 35 (27.34\%), followed by 31 to 40 years $26(20.31 \%)$ (Table 
I). Male to female ratio is $1: 1.56$. Males $50(39.06 \%)$, females $78(60.94 \%)$ (Table II).

The maximum number of cases were seen during the monsoon season, i.e. $32(25 \%)$ cases in the month of June, followed by the post monsoon period, 26 (20.31\%) in September (Image II). Among the districts of north Karnataka the most affected was Dharwad 83 (64.84\%) followed by Haveri 21 (16.41\%) (Table III). Increased in the hospitalisation of cases was seen during the study period as very few samples were received from the Out Patient Departments (Table IV).

\section{Discussion}

A total of 555 Chikungunya suspected serum samples were tested, of which 128 (23.06\%) samples were positive for Anti - Chikungunya IgM antibodies. Similar seroprevelance was noted in the study conducted by Shaikh Mohd Habeeb et al and Krishna et al. ${ }^{6,7}$ However lower prevalence was noted in the studies conducted by Mudurangaplar B et al. at Vijayapur and Mita D et al. at Chamarajnagar. ${ }^{8,9}$ The decreasing trend of prevalence of Chikungunya infection was seen from 2013 to 2016 i.e. $33.08 \%, 30.72 \%, 15.89 \%$ and $8.57 \%$ in 2013, 2014, 2015 and 2016 respectively in the present study.

There was no mortality but morbidity was high as the most affected population belongs to the productive age group of 21-40 years (47.37\%). Less affected were the paediatric age groups and least affected are the elderly ones. The low prevalence of Chikungunya infection among the extremes of age groups could be due to the reduced outdoor activities and over protected living. Females were more affected than males. Male to female ratio is 1:1.56. Similar trend was seen in the study conducted by Mudurangaplar. B et al. ${ }^{7}$ The present study included the serum samples of patients from 4 different districts of north Karnataka, namely; Dharwad, Gadadg, Haveri and Koppal along with 1 costal district i.e. Uttara kannada of Karnataka state. Among these 5 districts the maximum number of samples were received from Dharwad district and the same is most affected 83 (64.84\%) followed by Haveri 21 (16.41\%). Number of cases was more during monsoon month, June (29.74\%). This type of seasonal variation was seen in most of the studies, this could be because of the increased vector density during the rainy season. ${ }^{7,8}$ Majority of the patients required hospitalization; whereas $13.64 \%$ of the patients in 2013 and $37.26 \%$ in 2014 and $44.44 \%$ in 2016 were treated on Out Patient basis (Table IV). All the patients presented with fever, joint pain and headache which are the commonest symptoms of Chikungunya fever. Whereas altered sensorium was seen in $2.34 \%$ of the seropositive cases.

\section{Fig. 1: Seropositivity of Chikungunya of 4 years}

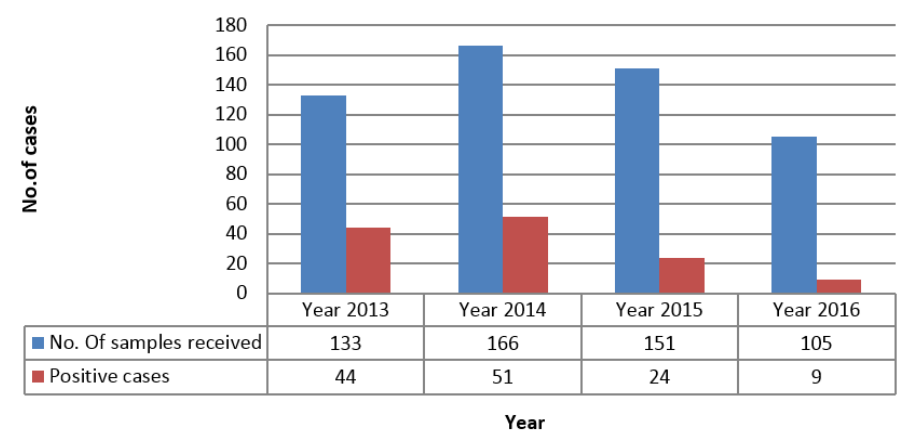

Fig. 2: Seasonal distribution of Chikungunya seropositive cases

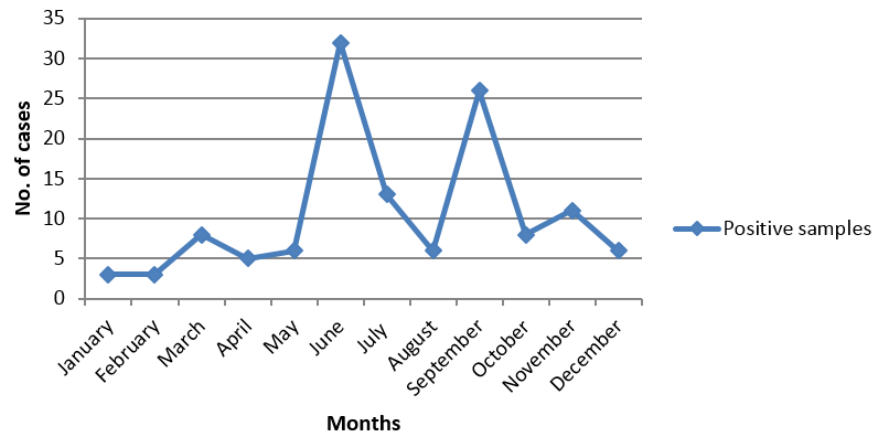


Table 1: Age wise distribution of Chikungunya seropositive cases

\begin{tabular}{|l|c|c|c|c|c|}
\hline Age group & $\mathbf{2 0 1 3}$ & $\mathbf{2 0 1 4}$ & $\mathbf{2 0 1 5}$ & $\mathbf{2 0 1 6}$ & $\begin{array}{c}\text { Total } \\
\text { positive }\end{array}$ \\
\hline $0-10 \mathrm{yrs}$ & 05 & 01 & 3 & 02 & $11(8.59 \%)$ \\
\hline 11-20yrs & 04 & 05 & 1 & 01 & $11(8.59 \%)$ \\
\hline 21-30yrs & 08 & 16 & 9 & 02 & $35(27.34 \%)$ \\
\hline 31-40yrs & 07 & 14 & 3 & 02 & $26(20.31 \%)$ \\
\hline $41-50 \mathrm{yrs}$ & 09 & 07 & 2 & 01 & $19(14.84 \%)$ \\
\hline $51-60 \mathrm{yrs}$ & 07 & 05 & 3 & 01 & $16(12.5 \%)$ \\
\hline 61-70yrs & 04 & 02 & 2 & 00 & $08(6.25 \%)$ \\
\hline 71-80yrs & Nil & 01 & 0 & 00 & $01(0.78 \%)$ \\
\hline $81-90 \mathrm{yrs}$ & 0 & 0 & 1 & 00 & $01(0.78 \%)$ \\
\hline Total & 44 & 51 & 24 & 09 & 128 \\
\hline
\end{tabular}

Table 2: Gender wise distribution of Chikungunya seropositive cases

\begin{tabular}{|l|c|c|c|c|c|}
\hline & $\mathbf{2 0 1 3}$ & $\mathbf{2 0 1 4}$ & $\mathbf{2 0 1 5}$ & $\mathbf{2 0 1 6}$ & Total Positive \\
\hline Male & $23(52.27 \%)$ & $13(25.49 \%)$ & $11(45.83 \%)$ & $03(33.33 \%)$ & $50(39.06 \%)$ \\
\hline Female & $21(47.73 \%)$ & $38(74.51 \%)$ & $13(54.17 \%)$ & $06(66.67 \%)$ & $78(60.94 \%)$ \\
\hline
\end{tabular}

Table 3: District wise distribution of Chikungunya seropositive cases

\begin{tabular}{|l|c|c|c|c|c|}
\hline \multicolumn{1}{|c|}{ District } & $\mathbf{2 0 1 3}$ & $\mathbf{2 0 1 4}$ & $\mathbf{2 0 1 5}$ & $\mathbf{2 0 1 6}$ & Total \\
\hline Dharawad & $15(34.1 \%)$ & $43(84.31 \%)$ & $19(79.17 \%)$ & $06(66.67 \%)$ & $83(64.84 \%)$ \\
\hline Gadag & $12(27.27 \%)$ & $05(9.8 \%)$ & 00 & 00 & $17(13.28 \%)$ \\
\hline Haveri & $11(25 \%)$ & $03(5.88 \%)$ & $04(16.67 \%)$ & $03(33.33 \%)$ & $21(16.41 \%)$ \\
\hline Uttarakannada & $06(13.64 \%)$ & 00 & 00 & 00 & $06(4.69 \%)$ \\
\hline Koppal & 00 & 00 & $01(4.17 \%)$ & 00 & $01(0.78 \%)$ \\
\hline Total & 44 & 51 & 24 & 09 & 128 \\
\hline
\end{tabular}

Table 4: Hospitalisation of Chikungunya seropositive patients.

\begin{tabular}{|l|c|c|c|c|}
\hline & $\mathbf{2 0 1 3}$ & $\mathbf{2 0 1 4}$ & $\mathbf{2 0 1 6}$ & Total \\
\hline Hospitalised cases & $38(86.37 \%)$ & $32(62.75 \%)$ & $05(55.56 \%)$ & $75(58.59 \%)$ \\
\hline OPD cases & $06(13.64 \%)$ & $19(37.26 \%)$ & $04(44.44 \%)$ & $29(41.41 \%)$ \\
\hline Total & 44 & 51 & 09 & 104 \\
\hline
\end{tabular}

\section{Conclusion}

The seroprevalence of Chikungunya in the present study was $23.06 \%$ with high frequency in the monsoon months and affecting the productive age group of the population. Screening for Chikungunya and other arboviral infections is necessary because though the clinical features are similar the outcomes and management may vary. Chikungunya continues to be the major health concern and indicates the need for appropriate strategies for vector control to prevent the transmission of infection.

Funding: No funding sources.

Conflict of interest: None declared.

\section{References}

1. Chhabra M, Mittal V, Bhattacharya D, Rana U, Lal S. Chikungunya fever: A re-emerging viral infection. Indian J Med Microbiol 2008;26:5-12.

2. Text book of Medical Microbiology jawetz, Melnick \& Adelbergs $24^{\text {th }}$ edition.

3. Kaur P, Ponniah M, Murhekar MV, Ramachandran V, Ramachandran R, Raju HK, et al. Chikungunya outbreak, South India, 2006. Emerg Infect Dis 2008;14:1623-5.
4. Balasubramaniam SM, Krishnakumar J, Stephen T, Gaur $\mathrm{R}$, Appavoo N. Prevalence of chikungunya in urban field practice area of a private medical college, Chennai. Indian J Community Med 2011;36:124-7.

5. Cecilia, D., 2014. Current status of dengue and chikungunya in India. WHO South-East Asia J Public Health 3(1):22-7.

6. Shaikh Mohd Habeeb et al. Seroprevalence of chikungunya cases in a tertiary care hospital in Mumbai. MedPulse Int J Microbiol 2017;4(1):1-3.

7. P. Divya and S. Krishna, Seroprevalence of Chikungunya virus infection in Ballari and nearby districts of Karnataka. Int J Med Microbiol Tropical Dis 2016;2(4):175-77.

8. Mudurangaplar B and Peerapur B V, Seroepidamological Survey of Chikungunya in and Around Region of Bijapur (North Karnataka). J Clin Diagnostic Res 2015;9(5):DC01-DC02.

9. Mita D. Wadekar, J.V. Sathish and Trupti B. Naik. Seroprevalence of Chikungunya among Febrile Patients in a Tertiary Care Hospital. Int J Curr Microbiol App Sci 2017;6(10):1713-17.

How to cite this article: S. Mahesh, Chikkaraddi U., R. Smitha, A. Divya. Seroprevalence of chikungunya fever in a tertiary care hospital in North Karnataka. Int $J$ Med Microbiol Trop Dis 2018;4(4):240-42. 